\title{
Phantom Fighters: Coping Mechanisms of Amputee Patients with Phantom Limb Pain: A Longitudinal Study
}

\author{
Daniella Margalit ${ }^{1,2 *}$, Eyal Heled ${ }^{3}$, Corinne Berger ${ }^{4}$, Hod Katzir ${ }^{5}$ \\ ${ }^{1}$ Department of Orthopedic Rehabilitation, Sheba Medical Center, Ramat Gan, Israel; ${ }^{2}$ Department of Psychology, Ariel University, \\ Ariel, Israel; ${ }^{3}$ The Day Care Rehabilitation Unit, Sheba Medical Center, Ramat Gan, Israel; ${ }^{4}$ Pain Rehabilitation Department, Sheba \\ Medical Center, Ramat Gan, Israel; ${ }^{5}$ Department of Psychology, Bar-Ilan University, Ramat Gan, Israel. \\ Email: *daniella.margalit@sheba.health.gov.il
}

Received October $8^{\text {th }}, 2013$; revised November $7^{\text {th }}, 2013$; accepted November $12^{\text {th }}, 2013$

Copyright (C) 2013 Daniella Margalit et al. This is an open access article distributed under the Creative Commons Attribution License, which permits unrestricted use, distribution, and reproduction in any medium, provided the original work is properly cited.

\begin{abstract}
Phantom Limb Pain (PLP) is a phenomenon commonly observed in orthopedic rehabilitation units that can have detrimental effects on patients' functioning. Psychological aspects of PLP have been widely investigated showing that some coping mechanisms are advantageous at certain points but not at others. However, the mechanisms related to positive adjustment to PLP during the course of rehabilitation have not been adequately examined. The aim of the study was to investigate the relationship between PLP and coping mechanism at two points during the rehabilitation process. Thirty one orthopedic inpatients, who had undergone lower-limb amputation following diabetic complications, rated their pain levels and mental coping strategies. The Ways of Coping Checklist, Life Orientation Test, and the McGill Pain Questionnaire, 1 - 15 days post-surgery and six months post-surgery were used for evaluation. Denial was found to be negatively correlated with PLP shortly after amputation. In contrast, optimism was found to be negatively correlated with PLP six months after the surgery. Emotion-focused coping mechanisms were found to be positively correlated with PLP. It is concluded that denial during the early stages of recuperation and optimism at later stages of rehabilitation is associated with reduced PLP. Awareness of these mental processes by both medical staff and family members may enable acceptance of these processes and thus facilitate patients' rehabilitation.
\end{abstract}

Keywords: Phantom Limb Pain; Mental Coping Mechanisms; Denial; Optimism

\section{Introduction}

Phantom Limb Pain (PLP) refers to painful sensations in an amputated or denervated part of the body [1]. These painful sensations are reported by $50 \%-85 \%$ of limb amputees beginning a short period after the procedure, with the reported episodes ranging from a minimum of several weeks per year to daily occurrences [2-4].

PLP is a challenge to caregivers and researchers in multi-disciplinary fields, and is sometimes detrimental to the sufferers. The occurrence of PLP can substantially disrupt the rehabilitation process, and can have serious consequences for the health and functioning of the patient [5]. These consequences might be physical, emotional or functional [5-12].

The perception of the etiology of PLP has changed substantially over time. Initially, PLP was perceived as

${ }^{*}$ Corresponding author. primarily psychological, however later, physiological explanations were proposed to explain the source of the phenomenon $[12,13]$. Current views maintain that an integrative bio-psycho-social approach is mandatory in order to better understand PLP [4].

Research on psychological factors related to PLP adjustment revealed positive correlations between pain and various psychiatric disorders, such as: depression, anxiety, stress, post-traumatic stress disorder, which may increase pain sensation. Cognitions have also been studied and catastrophizing was associated with pain. However, perceived control was found to be negatively correlated with pain sensations $[4,11,15-21]$.

Various coping mechanisms help amputee patients deal with pain [22]. Moreover, coping styles were found to be important predictors of psychosocial adjustment. For example, the psychosocial functioning of adults with acquired limb amputations was shown to be significantly 
related to the use of coping strategies [23]. Folkman and Lazarus [24] identified two main coping mechanisms: emotion-focused coping and problem-focused coping. According to this model, coping refers to the cognitive, emotional, and behavioral efforts aimed at keeping a balance between the person and the environment. Coping has two main functions: to regulate distress (emotionfocused coping) and to take actions to change and improve the situation (problem-focused coping). Problemfocused coping is related to a special form of emotionfocused coping, namely, "emphasizing the positive" which facilitates problem-focused coping [24]. Studies have shown emotion-focused coping to be associated with poor psychosocial outcomes [25-27].

Optimism (defined as a generalized expectation that future outcomes will be positive) was also found to be correlated with coping in patients with amputation $[28,29]$. Dunn [30] showed that having an optimistic disposition was associated with lower levels of depression and higher levels of self-esteem during the rehabilitation process after lower-limb amputation. Horgan and MacLachlan [31] demonstrated that respondents with high levels of optimism were more likely to search for positive meanings for their amputations. Furthermore, additional research showed a correlation between optimism and good rehabilitation outcomes [32,33].

A broadly acknowledged coping mechanism specifically found to be a common defense mechanism in the etiology of PLP is denial, that is, the refusal to believe that the stressor exists or the attempt to act as though the stressor is not real [34]. People who experience the loss of a limb have been shown to go through the five stages of grief also experienced by people who are dying: denial, anger, bargaining, depression, and acceptance $[8,35]$. Research shows that denial of the implications of an amputation (as a type of emotion-focused coping) is a positive short-term coping style following amputation [36]. However, in the long term, denial is associated with higher levels of depression and hostility and poor adjustment $[37,38,19]$.

While coping mechanisms and psychosocial adjustment in amputees have been studied, little is known about the psychological processes associated with PLP reduction during rehabilitation of lower-limb loss. Elaborating on the psychological aspects of this phenomenon may add an additional perspective to caregivers' understanding of coping with PLP.

Therefore, the aim of this study was to examine the correlation between coping mechanisms adopted by patients and PLP at two different points in time, following lower-limb amputation: a few days after the procedure, and six months later: a point in time when stump pain should have been resolved and when PLP would be deemed to be chronic [2], indicating a different stage in coping with pain.

We hypothesize that the coping mechanisms for pain management that are more prevalent a few days after surgery (such as denial and other emotion-focused strategies) would be negatively correlated with pain sensations [37]. However, these same coping mechanisms would be positively correlated with PLP six months later.

\section{Methods}

\subsection{Ethics Statement}

All participants received written and oral instructions of the research aims and procedures and gave informed written consent. This study was approved by the local ethic committee of Sheba Medical Center and Bar-Ilan University and performed in accordance with the Declaration of Helsinki.

\subsection{Participants}

The study sample consisted of 31 lower-limb amputee patients suffering from diabetes ( 28 men and 3 women) who were hospitalized in the orthopedic department of the Sheba Medical Center. All patients with reported PLP (as opposed to those reported as having stump pain or phantom sensations), as detailed in their medical records were enrolled in the study. No patients approached were subsequently excluded from the study. Of the participants, 21 were below-knee amputees, 4 were above-theknee amputees, and 6 were foot amputees. The selection criteria for the group were as follows: 1 . Patients who suffered from diabetes and had above- or below-knee amputation surgery; 2. Patients who experienced phantom limb pain; 3. Patients for whom a maximum of fifteen days had elapsed since the operation; and 4. Patients with no chronic pain complaints other than those associated with the amputation.

The use of drugs, including painkillers, major and minor tranquilizers, and muscle relaxants was prevalent, with $71 \%$ of the patients reporting drug use. Table 1 provides a demographic breakdown of the sample.

Table 1. Demographic and clinical data of the patients $(n=$ 31).

\begin{tabular}{cccc}
\hline & Maximum & Minimum & Mean (SD) \\
\hline Age (years) & $55(7.12)$ & 75 & 45 \\
Education (years) & $11.34(3.12)$ & 17 & 5 \\
Time since amputation & $9.29(3.23)$ & 15 & 4 \\
$\begin{array}{c}\text { (days) } \\
\text { Present Pain Intensity }\end{array}$ & & & \\
indices & & 5 & 1 \\
At present & $1.64(0.52)$ & 5 & 1 \\
Minimum level & $1.29(0.52)$ & 3 & 2 \\
Maximum level & $4.03(1.01)$ & 5 & \\
\hline
\end{tabular}




\subsection{Instruments}

The Ways of Coping Checklist (WOCC) is a measure that operationalizes and quantifies coping capabilities [24]. This checklist was administered in its translated and validated Hebrew version $[39,40]$. The instrument is a 42-item measure, utilizing a 5-point scale format, with responses ranging from 0 (not appropriate) to 4 (regularly used). The scores of the WOCC are produced by calculating the means of the responses.

The questionnaire consists of four subscales: a problem-focused coping strategy (PF; e.g., "I planned a course of action and followed it"), an emotion-focused coping strategy (EF; e.g., "I wish I had the ability to change the way I feel"), a seeking-social-support coping strategy (SSS; e.g., "I accept sympathy and understanding from others"), and denial (e.g., "I tried to forget the whole thing") [40]. A high score on a specific subscale indicates greater use of the coping strategy measured by the subscale. The internal reliability of the WOCC was tested using Cronbach's alpha coefficient; the coefficient confirmed satisfactory internal reliability of the subscales $(\mathrm{PF}=0.88, \mathrm{EF}=0.82, \mathrm{SSS}=0.86$, denial $=0.74)$.

The Life Orientation Test (LOT) measures generalized optimism [28]; that is, it tests individuals' sense of the probability that hopeful expectations will indeed materialize. The Hebrew version of the questionnaire was administered to the patients [41]. The LOT scale is comprised of twelve items: four positive items (e.g., "I am always optimistic about the future"), four negative items (e.g., "Things never work out the way I want them to"), and four distracters (e.g., "I find it important to keep busy"). The LOT is rated on a 4-point scale ranging from 1 (I agree very much) to 4 (I disagree very much). A high score on this scale indicates a high level of optimism.

The McGill Pain Questionnaire (MPQ), compiled by Melzack [42], was used in its validated Hebrew translation form [43-45]. The MPQ assesses qualitative components of pain and differentiates among different aspects of pain. Although the scale is made up of four parts, we made use of the Present Pain Intensity (PPI) scale, which consists of six items, rated from 1 (mild) to 5 (excruciating). When presented with this questionnaire, respondents were asked to rate how well a statement matches their PLP sensation at present, at its minimum level, at its maximum level, and when experiencing other types of pain (toothache, headache, and stomachache). We used the values of the three initial items.

\subsection{Procedure}

Personal data on the patients were obtained from their medical records. Patients who met inclusion criteria were approached in their room a few days after the amputation procedure. The researcher introduced himself and explained the research and its goals while emphasizing the two-stage procedure. If the patient agreed to proceed, he or she was given the informed consent form and, after signing, was asked to complete the questionnaire. Six months later, the patients were contacted via telephone and the questionnaires were re-administered.

\subsection{Analytic Strategy}

All analyses were conducted using SPSS (SPSS-15 Inc., Chicago, Illinois). One-way analysis of variance (ANOVA) was used to compare WOCC indices of patients in the hospitalization stage, followed by Tukey post-hoc test. In order to test the correlation between the mental variables and Present Pain Intensity in both time periods, Pearson correlation coefficient was employed. Significance was set at $\alpha<0.05$.

\section{Results}

Comparison of WOCC indices in the hospitalization phase, revealed a significant difference between the different indices shortly after the amputation procedure $(\mathrm{F}(3,28)=91.69, \mathrm{p}<0.001)$. Tukey post hoc test revealed that denial of life-long implications of the surgery was the most commonly employed coping mechanism, whereas seeking social support was the least common (see Table 2 for the data).

Table 3 presents correlation coefficients between optimism and coping abilities, and Present Pain Intensity at the first administration and at the second phase of the study. That is, the scores on the same questionnaires re-

Table 2. Means (standard deviations) and ranges of the WOCC $(\mathbf{n}=31)$.

\begin{tabular}{cccc}
\hline Variable & Mean (SD) & Minimum & Maximum \\
\hline Problem-focused & $2.59(0.57)$ & 1.5 & 3.7 \\
Emotion-focused & $2.57(0.55)$ & 1.4 & 3.5 \\
Seeking social support & $2.52(0.64)$ & 1.3 & 3.7 \\
Denial & $2.65(0.79)$ & 1.2 & 4 \\
\hline
\end{tabular}

Table 3. Pearson correlations between scores on the WOCC, LOT, and PPI indices of recently amputated respondents $(\mathbf{n}=31)$.

\begin{tabular}{|c|c|c|c|c|}
\hline & At present & $\begin{array}{c}\text { In } \\
\text { hospitalization }\end{array}$ & Maximum & $\begin{array}{c}\text { Six } \\
\text { months }\end{array}$ \\
\hline & At present & $\begin{array}{c}\text { Minimum } \\
\text { Level }\end{array}$ & Level & At present \\
\hline Optimism & -0.02 & -0.06 & -0.19 & $-0.44^{*}$ \\
\hline Problem-focused & 0 & -0.05 & 0 & 0.01 \\
\hline Emotion-focused & 0.01 & -0.02 & 0.23 & $0.45^{*}$ \\
\hline $\begin{array}{l}\text { Seeking social } \\
\text { support }\end{array}$ & 0.22 & 0.09 & 0.2 & 0.03 \\
\hline Denial & $-0.31^{*}$ & -0.25 & 0.17 & 0.33 \\
\hline
\end{tabular}


administered six months after amputation.

\section{Discussion}

The current study examined the mental coping mechanisms that are associated with PLP at two points in time. In the first stage, a few days post-amputation, the most employed defense mechanism reported by PLP patients, was denial, whereas seeking social support was the least employed. In addition, we found denial to be negatively correlated with PLP a few days after the operation, while six months after surgery, optimism was found to be negatively correlated with PLP. Finally, a positive correlation was found between emotion-focused mechanisms and PLP at six months post surgery, showing that this mechanism is associated with PLP a considerable period of time following the surgical intervention.

Our results complement findings by Pucher et al. [1] who concluded that patients' coping strategies affect their experience of pain, denial, in particular, was found to be associated with less reported pain in the initial phase of trauma following surgery [36,37]. By disregarding the implications of the disability, denial may enable other mental resources to surface in order to cope with the physical aspects of the amputation. Hence, denial aids in focusing on regaining bodily capabilities [46]. The correlation between denial and lower pain levels demonstrates the tendencies of patients post lower limb amputation to "favor" this self focused coping mechanism over the interpersonal coping mechanism "seeking social support".

Furthermore, studies have shown that consistent use of emotion-focused coping mechanisms is associated with depression in lower limb amputation patients, while for example, denial, long after the surgery might also eventually result in high levels of depression and hostility $[47,36]$. Our results add to this, by showing that use of emotion-focused coping mechanisms in general, six months after surgery is correlated with higher phantom limb pain sensation, indicating that this strategy is negatively associated with some aspects of rehabilitation.

On the other hand, it appears that adopting an optimistic view six months post amputation is associated with low levels of PLP. Optimism may instill meaning in the amputation, providing one with a greater sense of control over the event, as well as over the resulting disability [30,31].

This study has several limitations. Although there are numerous coping mechanisms and emotional constructs that most likely influence coping with PLP, we chose to explore a number of specific ones. Had we included additional constructs, we may have obtained a broader and clearer picture of the factors associated with this phenomenon. In addition, our sample included patients with lower-limb amputations at various sites, constituting a diverse population. More homogenous samples in terms of the physical location of the amputation may aid in further clarifying interactions between coping mechanisms and PLP.

Furthermore, future studies should examine other aspects associated with lower-limb PLP to expand our grasp of this phenomenon, and should focus on patients who have undergone upper-limb amputation as well. The work presented here focuses on the psychological domain in relation to pain prediction. However, in light of the need for a comprehensive perspective, future researchers should study the interaction of physical, social, and psychological variables together on long-term postamputation PLP.

In conclusion, from a psychological standpoint, those who deny the consequences of the amputation shortly after it has occurred may suffer less from PLP. Moreover, optimism is also associated with lower PLP six months after surgery, whereas emotion-focused coping mechanisms are associated with higher levels of PLP. In consequence, it seems that the relation between PLP and coping mechanisms indicates the six months post-amputation as a relevant time frame for rehabilitation which patients and caregivers of which caregivers should be aware.

The implications of this study lie in the importance of understanding the underlying mental processes experienced by patients shortly and six months after surgery. Caregivers such as physicians, rehabilitative therapists, and family members can be educated regarding these mental processes and the emotional manifestations they should expect to see in patients following amputation. They can then be directed to be accepting of coping mechanisms positively associated with rehabilitation such as denial of disability in early stages of rehabilitation, allowing patients to utilize this coping mechanism at that point in time.

\section{REFERENCES}

[1] I. Pucher, W. Kickinger and O. J. Frischenschlager, "Coping with Amputation And Phantom Limb Pain," Journal of Psychosomatic Research Vol. 46, No. 4, 1999, pp. 379383. http://dx.doi.org/10.1016/S0022-3999(98)00111-1

[2] C. Richardson, S. Glenn, M. Horgan and T. Nurmikko, "A Prospective Study of Factors Associated with the Presence of Phantom Limb Pain Six Months after Major Lower Limb Amputation in Patients with Peripheral Vascular Disease," Journal of Pain Vol. 8, No. 10, 2007, pp. 793-801. http://dx.doi.org/10.1016/i.jpain.2007.05.007

[3] R. A. Sherman, C. J. Sherman and I. Parker, "Chronic Phantom and Stump Pain Among American Veterans: Results of A Survey," Pain, Vol. 18, No. 1, 1984, pp. 1883-1895.

http://dx.doi.org/10.1016/0304-3959(84)90128-3 
[4] M. A. Hanley, M. P. Jensen, D. M. Ehde, A. J. Hoffman D. R. Patterson and L. R. Robinson, "Psychosocial Predictors of Long-Term Adjustment to Lower-Limb Amputation and Phantom Limb Pain," Disability and Rehabilitation, Vol. 26, No. 14-15, 2004, pp. 882-893. http://dx.doi.org/10.1080/09638280410001708896

[5] R. Casale, L. Alaa, M. Mallick and H. Ring, "Phantom Limb Related Phenomena and Their Rehabilitation after Lower-Limb Amputation," European Journal of Physical and Rehabilitation Medicine, Vol. 45, No. 4, 2009, pp. 559-566.

[6] R. A. Carabelli and W. C. Kellerman, "Phantom Limb Pain Relief by Tens to Contralateral Extremity," Archives of Physical Medicine and Rehabilitation, Vol. 66, No. 7, 1985, pp. 466-467.

[7] S. Millstein, D. Bain and G. A. Hunter "A Review of Employment Patterns of Industrial Amputees-Factors Influencing Rehabilitation," Prosthetics and Orthotics International, Vol. 9, No. 2, 1985, pp. 69-78.

[8] C. M. Parkes "Factors Determining The Persistence of Phantom Pain in The Amputee," Journal of Psychosomatic Research, Vol. 17, No. 2, 1973, pp. 97-108. http://dx.doi.org/10.1016/0022-3999(73)90010-X

[9] C. P. Van der Schans, J. H. B. Geertzen, T. Schoppen and P. U. Djikstra, "Phantom Pain and Health-Related Quality of Life in Lower Limb Amputees," Journal of Pain and Symptom Management, Vol. 24, No. 4, 2002, pp. 429-436. http://dx.doi.org/10.1016/S0885-3924(02)00511-0

[10] M. Marshall, E. Helmes and A. B. Deathe, "Comparison of Psychosocial Functioning and Personality in Amputee and Chronic Pain Populations," The Clinical Journal of Pain, Vol. 8, No. 4, 1992, pp. 351-357. http://dx.doi.org/10.1097/00002508-199212000-00010

[11] A. S. Whyte and L. J. Carroll, "The Relationship between Catastrophizing and Disability in Amputees Experiencing Phantom Pain," Disability and Rehabilitation, Vol. 26, No. 11, 2004, pp. 649-654. http://dx.doi.org/10.1080/09638280410001672508

[12] J. Katz and L. Gagliese, "Phantom Limb Pain: A Continuing Puzzle," In: R. J. Gatchel and D. C. Turk, Eds., Psychosocial Factors in Pain: Critical Perspectives, Guilford Press, New York, 1999, pp. 284-300.

[13] A. Hill, C. A. Niven and C. Knussen, "The Role of Coping in Adjustment to Phantom Limb Pain," Pain, Vol. 62, No. 1 1995, pp. 79-86. http://dx.doi.org/10.1016/0304-3959(94)00253-B

[14] M. P. Jensen, D. M. Ehde, A. J. Hoffman, D. R. Patterson, J. M. Czerniecki and L. R. Robinson, "Cognitions, Coping and Social Environment Predict Adjustment to Phantom Limb Pain," Pain, Vol. 95, No. 1, 2002, pp. 133-142. http://dx.doi.org/10.1016/S0304-3959(01)00390-6

[15] Z. M. Hawamdeh, Y. S. Othman and A. I. Ibrahim, “Assessment of Anxiety and Depression after Lower Limb Amputation in Jordanian Patients," Neuropsychiatric Disease and Treatment, Vol. 4, No. 3, 2008, pp. 627-633. http://dx.doi.org/10.2147/NDT.S2541

[16] B. Darnall, P. Ephraim, S. T. Wegener, et al., "Depressive Symptoms and Mental Health Service Utilization Among
Persons with Limb Loss: Results of A National Survey," Archives of Physical Medicine and Rehabilitation, Vol. 86, No. 4, 2005, pp. 650-658. http://dx.doi.org/10.1016/j.apmr.2004.10.028

[17] M. Asano, P. Rushton, W. C. Miller and B. A. Deathe, "Predictors of Quality of Life among Individuals who Have a Lower Limb Amputation," Prosthetics and Orthotics International, Vol. 32, No. 2, 2008, pp. 231-243. http://dx.doi.org/10.1080/03093640802024955

[18] P. V. Giannoudis, P. J. Harwood, G. Kontakis, et al., "Long-Term Quality of Life in Trauma Patients Following the Full Spectrum of Tibial Injury (Fasciotomy, Closed Fracture, Grade IIIB/IIIC Open Fracture and Amputation)," Injury, Vol. 40, No. 2, 2009, pp. 213-219. http://dx.doi.org/10.1016/j.injury.2008.05.024

[19] D. M. Desmond and M. MacLachlan, "Affective Distress and Amputation-Related Pain among Older Men with Long-Term, Traumatic Limb Amputations," Journal of Pain Symptom Management, Vol. 31, No. 4, 2006, pp. 362-368. http://dx.doi.org/10.1016/j.jpainsymman.2005.08.014

[20] B. A. Arnow, C. M. Blasey, M. J. Constantino, et al., "Catastrophizing, Depression and Pain-Related Disability,” General Hospital Psychiatry, Vol. 33, No. 2, 2011, pp. 150-156.

http://dx.doi.org/10.1016/j.genhosppsych.2010.12.008

[21] F. J. Keefe and D. A. Williams, "A Comparison of Coping Strategies in Chronic Pain Patients in Different Age Groups," Journal of Gerontology, Vol. 45, No. 4, 1990, pp. 161-165. http://dx.doi.org/10.1093/geronj/45.4.P161

[22] D. M. Desmond. “Coping, Affective Distress, and Psychosocial Adjustment among People with Traumatic Upper Limb Amputations," Journal of Psychosomatic Research, Vol. 62, No. 1, 2007, pp. 15-21. http://dx.doi.org/10.1016/j.jpsychores.2006.07.027

[23] C. S. Carver, M. F. Scheier and J. K. Weintraub, “Assessing Coping Strategies: A Theoretically Based Approach," Journal of Personality and Social Psychology, Vol. 56, No. 6, 1989, pp. 267-283.

http://dx.doi.org/10.1037/0022-3514.56.2.267

[24] R. S. Lazarus and S. Folkman, "Stress Appraisal, and Coping," Springer Publishing Company, New York, 1984.

[25] I. Dudkiewicz, R. Gabrielov, I. Seiv-Ner, G. Zelig and M. Heim, "Evaluation of Prosthetic Usage in Upper Limb Amputees," Disability and Rehabilitation, Vol. 26, No. 1, 2004, pp. 60-63. http://dx.doi.org/10.1080/09638280410001645094

[26] W. J. Gaine, C. Smart and M. Bransby-Zachary, "Upper Limb Traumatic Amputees. Review of Prosthetic Use," Journal of Hand Surgery, Vol. 22, No. 1, 1997, pp 73-76. http://dx.doi.org/10.1016/S0266-7681(97)80023-X

[27] C. M Ga Kooijman, P. U. Dijkstra, J. H. B. Geertzen, A. Elzinga, C. P. van der Schans, "Phantom Pain and Phantom Sensations in Upper Limb Amputees: An Epidemiological Study," Pain, Vol. 87, No. 1, 2000, pp. 33-41. http://dx.doi.org/10.1016/S0304-3959(00)00264-5

[28] M. F. Scheier and C. S. Carver, "Optimism, Coping, and 
Health: Assessment and Implications of Generalized Outcome Expectancies" Health Psychology, Vol. 4, No. 3, 1985, pp. 219-247. http://dx.doi.org/10.1037/0278-6133.4.3.219

[29] M. F. Scheier, C. S. Carver and M. W. Bridges, "Distinguishing Optimism from Neuroticism (and Trait Anxiety, Self-Mastery, and Self-Esteem): A reevaluation of the life orientation test," Journal of Personality and Social Psychology, Vol. 67, No. 6, 1994, pp. 1063-1078. http://dx.doi.org/10.1037/0022-3514.67.6.1063

[30] D. S. Dunn, "Well-being Following Amputation: Salutary Effects of Positive Meaning, Optimism, and Control," Rehabilitation Psychology, Vol. 41, No. 4, 1996, pp. 285302. http://dx.doi.org/10.1037/0090-5550.41.4.285

[31] O. Horgan and M. MacLachlan, "Psychosocial Adjustment to Lower-Limb Amputation: A Review," Disability and Rehabilitation, Vol. 26, No. 14-15, 2004, pp. 837850. http://dx.doi.org/10.1080/09638280410001708869

[32] A. MacBride, J. Rogers, B. Whylie and S. J. J. Freeman, "Psychosocial Factors in the Rehabilitation of Elderly Amputees," Psychosomatics, Vol. 21, No. 3, 1989, pp. 258-265. http://dx.doi.org/10.1016/S0033-3182(80)73701-5

[33] B. Rybarczyk, R. Edwards and J. Behel, "Diversity in Adjustment to A Leg Amputation: Case Illustrations of Common Themes," Disability and Rehabilitation, Vol. 26, No. 14-15, 2004, pp. 944-953. http://dx.doi.org/10.1080/09638280410001708986

[34] R. S. Lazarus, "The Costs and Benefits of Denial," In: S. Breznitz, Ed., The Denial of Stress, International Universities Press, New York, 1983, pp. 1-30.

[35] E. Kubler-Ross, "On Death and Dying," Macmillan, New York, 1968.

[36] H. Livneh, R. F. Antonak and J Gerhardt, "Psychosocial Adaptation to Amputation: The Role of Sociodemographic Variables, Disability-Related Factors, and Coping Strategies," International Journal of Rehabilitation Research, Vol. 22, No. 1, 1999, pp. 21-31. doi.:10.1097/00004356-199903000-00003

[37] C. Sjödahl, G. Gard and G. B. Jarnlo, "Coping after Trans-Femoral Amputation Due to Trauma or Tumor-A Phenomenological Approach," Disability and Rehabilitation, Vol. 26, No. 14-15, 2004, pp. 851-861. http://dx.doi.org/10.1080/09638280410001662996

[38] J. Walters, "Coping with Leg Amputation," American
Journal of Nursing, Vol. 81, No. 7, 1981, pp. 1349-1352.

[39] P. P. Vitaliano, J. Russo, J. E. Carr, R. D. Maiuro and J. Becker, "The Ways of Coping Checklist: Revision and Psychometric Properties," Multivariate Behavioral Research, Vol. 20, No. 1, 1985, pp. 3-26. http://dx.doi.org/10.1207/s15327906mbr2001_1

[40] Z. Solomon, E. Avitzur and M. Mikulincer, "Coping Resources and Social Function Following Combat Stress Reaction: A Longitudinal Study," Journal of Social and Clinical Psychology, Vol. 8, No. 1, 1989, pp. 87-96. http://dx.doi.org/10.1521/jscp.1989.8.1.87

[41] Z. German, "The Relationship between Procrastination and Guilt as A Basis for the Typology of Procrastinators and Non Procrastinators," Ph.D. Thesis, Tel Aviv University, Tel Aviv, 1990.

[42] R. Melzack, "The McGill Pain Questionnaire: Major Properties and Scoring Methods," Pain, Vol. 1, No. 3, 1975, pp. 277-299. http://dx.doi.org/10.1016/0304-3959(75)90044-5

[43] R. Defrin, A. Ohry, N. M. Blumen and G. Urca, "Acute Pain Threshold in Participants with Chronic Pain Following Spinal Cord Injury," Pain, Vol. 83, No. 2, 1999, pp. 275-282. http://dx.doi.org/10.1016/S0304-3959(99)00115-3

[44] A. Yaari, E. Eisenberg, R. Adler and J. Birkhan, "Chronic Pain in Holocaust Survivors," Journal of Pain and Symptom Management, Vol. 17, No. 3, 1999, pp. 181-187. http://dx.doi.org/10.1016/S0885-3924(98)00122-5

[45] Y. P. Talmi, A. Waller, M. Bercovici, et al., "Pain Experienced by Patients with Terminal Head and Neck Carcinoma," Cancer, Vol. 80, No. 6, 1997, pp. 1117-1123. http://dx.doi.org/10.1002/(SICI)1097-0142(19970915)80: 6<1117::AID-CNCR15>3.0.CO;2-B

[46] D. Arazi-Margalit, S. Rappaport, D. Neman, A. Fridman, Z. Tzadok, H. Azaryah, et al., "The Mental Reaction to Physical Disability," In: A. Bleich and Z. Solomon, Eds. Mental Disability. Medical, Research, Social, Legal and Rehabilitative Aspects, Ministry of Defense Publication, Tel-Aviv, 2002, pp. 201-259.

[47] N. S. Endler and J. D. Parker, "A Multidimensional Assessment of Coping: A Critical Evaluation," Journal of Personality and Social Psychology, Vol. 58, No. 5, 1990, pp. 844-854.

http://dx.doi.org/10.1037/0022-3514.58.5.844 